\title{
Hypertensive Pathologies in Peripartum: Complications and Maternal and Neonatal Outcome
}

\author{
Isango Idi Yves' ${ }^{1}$, Criss Koba Mjumbe ${ }^{2}$, Kabamba Nzaji Michel2 ${ }^{2}$ Malamba Lez Didier ${ }^{3}$, \\ Kakisingi Ngama Christian ${ }^{3}$, Kiopin Mubinda Patrick ${ }^{1}$, Mwilambwe Ngoy Steve1, \\ Manika Muteya Michel $^{3}$, Ngwe Thaba Jules ${ }^{1}$, Mwembo Tambwe Albert ${ }^{1,2}$, \\ Kalenga Muenze Prosper ${ }^{1,2}$
}

\begin{abstract}
${ }^{1}$ Department of Gynecology and Obstetrics, Faculty of Medicine of the University of Lubumbashi, Lubumbashi, DR Congo ${ }^{2}$ Department of Public Health of the University of the University of Lubumbashi, Lubumbashi, DR Congo ${ }^{3}$ Department of Internal Medicine, Faculty of Medicine of the University of Lubumbashi, Lubumbashi, DR Congo Email: *cryss_koba25@yahoo.fr
\end{abstract}

How to cite this paper: Yves, I.I., Mjumbe, C.K., Michel, K.N., Didier, M.L., Christian, K.N., Patrick, K.M., Steve, M.N., Michel, M.M., Jules, N.T., Albert, M.T. and Prosper, K.M. (2020) Hypertensive Pathologies in Peripartum: Complications and Maternal and Neonatal Outcome. Open Journal of Obstetrics and Gynecology, 10, 311-318. https://doi.org/10.4236/ojog.2020.1020027

Received: December 20, 2019

Accepted: February 23, 2020

Published: February 26, 2020

Copyright $\odot 2020$ by author(s) and Scientific Research Publishing Inc. This work is licensed under the Creative Commons Attribution International License (CC BY 4.0).

http://creativecommons.org/licenses/by/4.0/

\begin{abstract}
Introduction: Among the hypertensive pathologies of pregnancy, preeclampsia remains the entity responsible for pregnancy complications. Objective: The aim of this work was to determine the frequency of hypertensive pathologies in the peripartum, to determine the maternal and neonatal morbidity factors associated with preeclampsia on the one hand, and on the other hand, to other forms of hypertension in the peripartal period. Patients and methods: This is a cross-sectional study of hypertensive pathologies in per partum over a period of 15 months which have been included any pregnant, parturient and hypertensive childbirth. The data was analyzed using SPSS software version 21.0. Data positioning and dispersion parameters were studied. The factor analysis was performed by determining the odds ratio with a $95 \%$ confidence interval and a significance level set at $\mathrm{p} \leq 0.05$. Results: 142 cases of hypertension were collected from a total of 2988 deliveries, i.e. a frequency of hypertension of $4.8 \%$. The main form of high blood pressure (HBP) was the isolated $\mathrm{HBP}$ at $51.4 \%$. $60.3 \%$ of primiparas were preeclamptic [OR 2.47 (CI 1.25 4.91)], 63.2\% of preeclampsia did not follow prenatal consultations [OR 2.43 (CI 1.06 - 5.62)], 63.6\% of preeclampsia had moderate and severe threat premature delivery [OR 4.57 (CI 2.11 - 9.99)], neonatal hypoxia in the fifth minute was found in $34.4 \%$ of newborns of preeclamptic mothers [OR 3.02 (CI 1.44 6.34)], hypotrophy was observed in $41.4 \%$ of the cases in the preeclamptic patients [OR 5.41 (IC 1, from 55 to 19.57)]. Conclusion: Preeclampsia is significantly associated with maternal and neonatal morbidity.
\end{abstract}




\section{Keywords}

Hypertensive Pathology, PeriPartum, Complications, Maternal and Neonatal Outcomes

\section{Introduction}

Hypertensive disorders during pregnancy are divided into four entities, namely: chronic hypertension, isolated hypertension, preeclampsia and preeclampsia added to chronic hypertension [1]. This pregnancy-induced hypertensive syndrome forms a heterogeneous group of disease states, the common denominator of which is an increase in blood pressure during pregnancy [2]. In relation to the different types of hypertension during pregnancy, preeclampsia complicates $2 \%$ to $8 \%$ of pregnancies and is one of the three main causes of maternal morbidity and mortality in the world [3]. In the Democratic Republic of Congo, Sengeyi et al. [4], in a study on hypertensive disorders during pregnancy at the University Clinics of Kinshasa, found on 101 pregnant hypertensive patients 72 cases of preeclampsia, i.e. a frequency of $71 \%$. These authors have shown that among the hypertensive pathologies of pregnancy, preeclampsia is the entity that affects the maternal and fetal prognosis. In our environment, there is no study carried out on the theme of hypertensive pregnancy pathologies. This work is carried out in a very specific context in our community to try to propose a plan that would reduce by three quarters the maternal mortality rate through good care. The aim of this work was to determine the frequency of hypertensive pathologies in the peripartum, to determine the maternal and neonatal morbidity factors associated with preeclampsia on the one hand, and on the other hand, to other forms of hypertension in the peripartal period.

\section{Methodology}

This was a descriptive cross-sectional study carried out in two hospitals in the city of Lubumbashi in the Democratic Republic of Congo, the Lubumbashi university clinics and the south Gecamine hospital from January 2013 to March 2014 We constituted an exhaustive non-probabilistic sample of 142 hypertensive patients with as inclusion criteria, having presented a systolic blood pressure $(\mathrm{PAS}) \geq 140 \mathrm{mmHg}$ and or a diastolic blood pressure (PAD) $\geq 90 \mathrm{mmHg}$ in peripartum that is i.e. the ante, per and postpartum period. The study variables were blood pressure (BP) in the parturient, clinical, gynecological and obstetric parameters. Note that a second BP sample was taken one hour after the first sample from hypertensive patients and it was the second sample that was used in the study [5] [6].

A second BP sample was taken one hour after the first sample in hypertensive patients and it was the second sample that was used in the study [7]. Two types of validated sphygmomanometer have been used, the manual or aneroid 
hand-held sphygmomanometer type Primus Stabil 3 aneroide sphygmomanometer [8] and the electronic arm tensiometer type Nissei DSK-1011 [9]. Data encoding and analysis was done with Microsoft Excel and SPSS 21.0 software. We performed the relative frequency calculation and the association measurement. The significance level was $\mathrm{p} \leq 0.05$ with a $95 \%$ confidence interval.

\section{Results}

\subsection{Sociodemographic and Clinical Parameters}

Our study involved 142 hypertensive patients whose average age was $29 \pm 7.5$ years and (63.4\%) of them were between 19 and 34 years old. The average parity was $3.4 \pm 2.8$ deliveries and (53.5\%) of hypertensive patients had a gestational age between 37 and 42 weeks with a predominance of monofetal pregnancies at (92.3\%). In (73.2\%) the hypertensive patients followed the Near Birth Consultations and in the course of this there was a notion of history of hypertension in (3.5\%) whereas (54.9\%) of the patients reported being diagnosed with hypertension during antenatal care. According to the clinic, (51.4\%) of the patients had developed isolated hypertension and the type of hypertension according to albuminuria reveals that albuminuria was significant in (48.6\%) of the patients who presented with preeclampsia and associated chronic hypertension. Almost (78.2\%) of the hypertensive patients had received antihypertensive medical treatment and in (61.9\%) of the hypertensive patients, they delivered vaginally.

\subsection{Hypertensive Patients According to the Study Site and the Types of Hypertension}

The majority of hypertensive patients came from Gécamines-Sud hospital (5.4\%). Regarding the types of hypertension, $51.4 \%$ of the patients had developed an isolated hypertension whereas pre-eclampsia was diagnosed in $47.2 \%$ of the cases.

In Table 1, the factors that were significantly associated with preeclampsia compared to other types of hypertension: 1) primiparas were twice as likely to have preeclampsia as other types of hypertension. 2) The risk of developing preeclampsia compared to the types of hypertension was 4.57 when the hypertensive patient presented either a moderate MAP or a severe MAP. 3) Pregnant women who did not follow ANC were twice as likely to develop preeclampsia as other types of hypertension.

From the 37th week of amenorrhea, hypotrophy was represented in $41.4 \%$ of cases in pre-eclamptic patients and in patients who had presented other types of hypertension, it was represented in $11.5 \%$ of cases (Table 2 ).

The risk for pre-eclamptic patients of giving birth to a hypotrophic newborn was increased by 5.41 compared to other types of hypertension.

Table 3 shows that neonatal hypoxia at the 5th minute of life was $34.4 \%$ in preeclampsia and $11.4 \%$ in other types of hypertension. In preeclamptics, the risk of hypoxia in the 5th minute of life was 3.02 (CI 1.44 - 6.34) compared to 
Table 1. Hypertensive patients based on factors associated with preeclampsia.

\begin{tabular}{cccccccc}
\hline & \multicolumn{5}{c}{ Types of HBP } & OD IC at 95\% & P \\
\cline { 2 - 7 } Settings & \multicolumn{2}{c}{ PEE } & Other types & & \\
\cline { 2 - 8 } & $\mathrm{n}$ & $\%$ & $\mathrm{n}$ & $\%$ & & \\
\hline Primiparity $\mathrm{n}=58$ & 35 & 60.3 & 23 & 39.7 & $2.47(1.25-4.91)$ & 0.01 \\
MAP: HBP moderate and severe $\mathrm{n}=77$ & 49 & 63.6 & 28 & 36.4 & $4.57(2.11-9.99)$ & 0.00 \\
Prenatal consultation not followed $\mathrm{n}=38$ & 24 & 63.2 & 14 & 36.8 & $2.43(1.06-5.62)$ & 0.02 \\
\hline
\end{tabular}

MAP: medium arterial pressure; ANC: prenatal consultations.

Table 2. Association between types of hypertension and birth weight depending on the term of pregnancy.

\begin{tabular}{|c|c|c|c|c|c|c|}
\hline \multirow{3}{*}{ Types of HBP } & \multicolumn{4}{|c|}{ Birth weight from $37 \mathrm{AW}$} & \multirow{3}{*}{ OR CI at $95 \%$} & \multirow[t]{3}{*}{$\mathrm{p}$} \\
\hline & \multicolumn{2}{|c|}{$<2500 \mathrm{~g}$} & \multicolumn{2}{|c|}{$\geq 2500 \mathrm{~g}$} & & \\
\hline & $\mathrm{n}$ & $\%$ & $\mathrm{n}$ & $\%$ & & \\
\hline Preeclampsia $n=29$ & 12 & 41.4 & 17 & 58.6 & $5.41(1.55-19.57)$ & 0.00 \\
\hline Other types HBP $n=52$ & 6 & 11.5 & 46 & 88.5 & & \\
\hline \multirow[t]{4}{*}{ Total $\mathrm{n}=81$} & 18 & 22.2 & 63 & 77.8 & & \\
\hline & \multicolumn{4}{|c|}{ Birth weight before $37 \mathrm{AW}$} & & \\
\hline & \multicolumn{2}{|c|}{$<2500 \mathrm{~g}$} & \multicolumn{2}{|c|}{$\geq 2500 \mathrm{~g}$} & & \\
\hline & $\mathrm{n}$ & $\%$ & $\mathrm{n}$ & $\%$ & & \\
\hline Preeclampsia $n=26$ & 24 & 92.3 & 2 & 7.7 & & 0.22 \\
\hline other types HBP $n=14$ & 11 & 78.6 & 3 & 21.4 & & \\
\hline Total $n=40$ & 35 & 87.5 & 5 & 12.5 & & \\
\hline
\end{tabular}

AW: Amenorrhea week.

Table 3. Association between types of hypertension and APGAR at the 5th minute.

\begin{tabular}{|c|c|c|c|c|c|c|}
\hline \multirow{3}{*}{ Types of HBP } & \multicolumn{4}{|c|}{ APGAR $5^{\text {th }}$ minute } & \multirow[t]{3}{*}{ OR CI at $95 \%$} & \multirow[t]{3}{*}{$\mathrm{P}$} \\
\hline & \multicolumn{2}{|c|}{ Depress APGAR } & \multicolumn{2}{|c|}{ Good APGAR } & & \\
\hline & $\mathrm{n}$ & $\%$ & $\mathrm{~N}$ & $\%$ & & \\
\hline Preeclampsia $\mathrm{n}=58$ & 20 & 34.4 & 38 & 65.5 & $3.02(1.44-6.34)$ & 0.00 \\
\hline other types $n=70$ & 8 & 11.4 & 62 & 88.6 & 1 & \\
\hline Total $n=128$ & 28 & 21.9 & 100 & 78.1 & & \\
\hline
\end{tabular}

other types of hypertension. Discussion during the study period, 142 cases of hypertension was identified in a population of 2988 patients, representing a prevalence of $4.8 \%$. This prevalence is limited because it related to the perinatal period. In developed countries, the frequency of hypertension during pregnancy varies from $5 \%$ to $10 \%$ [6]. The steady increase in the prevalence of obesity, metabolic syndrome, and hypertension is also accompanied by an increase in the prevalence of hypertension in pregnancy [10]. In Africa prevalences vary from 
one country to another: $2.99 \%$ in Antanarivo [11], 8.2\% in Yaoundé [12], 8.6\% in Bamako [13], $17.05 \%$ in Niger [14], and 6.6\% in Kinshasa [4]. In relation to the different types of hypertension in peripartum, in our series, isolated hypertension was the most common hypertensive type at $51.4 \%$ followed by preeclampsia at $47.2 \%$. Some studies carried out in hospitals have found frequencies that can be superimposed on ours such as that of Madagascar where isolated hypertension was the predominant hypertensive form at 52\% [11]. In Dakar, preeclampsia was the main hypertensive entity at $47 \%$ [15], other studies, on the other hand, found frequencies of preeclampsia higher than ours, 54\% in Bamako [16], 71\% in Kinshasa [4]. Several authors have found significant statistical links between primiparity and preeclampsia, including Meviel et al. [17] who noted in their work that primiparity multiplies by 2 the risk of presenting preeclampsia (OR = 2.67; CI [1.67 - 4.29]), Boubacar et al. [16] found that $44.5 \%$ of primiparas had developed preeclampsia $(\mathrm{p}=0.00$ ). In our study, primiparity was observed in $60.3 \%$ of cases in preeclamptics with a risk for the primiparous to present preeclampsia of 2.47 (CI 1.25 - 4.91) compared to other types of HBP. The mechanisms allowing the semiallogenic trophoblastic cell to invade maternal tissues by thwarting the maternal processes of self-recognition may be defective. An immunological reaction therefore occurs due to the patient's first exposure to trophoblastic villi containing antigens of fetal and therefore paternal origin. Thus the hypothesis of an immunological maladaptation in the occurrence of preeclampsia is evoked [18]. The risk of developing preeclampsia compared to types of hypertension was 4.57 when the hypertensive patient had either moderate or severe MAP. Patients with mild hypertension generally have as good a prognosis as in normal pregnancies.

In contrast, maternal and perinatal morbidity is substantially increased during severe hypertension and the rates of placental abruption, cesarean delivery, intrauterine growth retardation and prematurity are comparable to those observed in severe preeclampsia. These patients should therefore benefit from follow-up identical to that established during severe pre-eclampsia [19]. We found that $63.2 \%$ of patients who had not followed ANC were pre-eclamptic and had 2.4 times the risk of pre-eclampsia (CI 1.06 - 5.62) compared to the types of hypertension. In Morocco, Laghzaoui et al. [20] reported that among pre-eclamptics, pregnancies not followed exceeded $70 \%$. Although regular monitoring of pregnancy does not prevent the occurrence of preeclampsia, it still allows early detection and prevention of its development towards complications. All told, prenatal consultations are therefore a preferred means of reducing the occurrence of these complications [21]. We believe that the relationship established between the non-follow-up of ANC and preeclampsia, in our study, should be considered in the sense that patients at risk of developing preeclampsia were not detected early during pregnancy, because according to Sibai et al. [22], the early detection of women at risk of preeclampsia is considered to be a key to the development of a preventive treatment whose effectiveness could depend on the earliness of its 
introduction. The risk for pre-eclamptic patients of giving birth to a hypotrophic newborn was increased by 5.41 compared to other types of hypertension. Ngwe et al. [23], in a case-control study, found that the risk for a hypertensive pregnant woman of having a fetus in IUGR was 2 times higher than for a non-hypertensive pregnant woman $(\mathrm{OR}=2.44)$.

According to the recommendations of the National College of French Gynecologists and Obstetricians [24], preeclampsia multiplied the risk of RCIU, by a factor of 5 to 12 depending on the severity of the attack. Indeed, previously, Meekins et al. [25] have shown that in the case of preeclampsia, the invasion of the decidual arterioles by the extravillous cytotrophoblasts decreases by $56 \%$ and that the invasion of the myometrial arteries decreases from $76 \%$ to $18 \%$. To this defect of invasion is added a defect in their endothelial remodeling by the extravillous cytotrophoblasts. Endothelial cells are not replaced by trophoblasts, and the smooth muscle cell layer is not changed. Thus the uterine arterioles have a smaller diameter and retain their vasoconstrictor potential [26]. Subsequently, this results in a decrease in uteroplacental flow, which disrupts fetal-maternal exchanges [27]. In preeclamptics, the risk of hypoxia in the 5th minute of life was 3.02 (CI 1.44 - 6.34) compared to other types of hypertension. Fatoumata et al. [28] found a significant association between preeclampsia and weak APGAR. Neonatal hypoxia at the 5th minute is correlated with cerebral palsy and death [29]. Although neonatal depression would be related to placental ischemia, we believe that the circumstances of childbirth coupled with measures of neonatal resuscitation would be avenues to be investigated later to establish the causal links.

\section{Conclusion}

Isolated hypertension was the most frequent hypertensive form in peripartum. Preeclampsia was significantly the hypertensive entity significantly associated with the parameters of maternal and neonatal morbidity. For the future, we suggest carrying out more in-depth studies in order to be able to look for other factors of maternal, fetal and neonatal comorbidity in relation to hypertensive gravidary pathologies in our environment.

\section{Author Contribution}

All the authors of this article have made a significant contribution to the design, implementation and/or analysis and interpretation of the data, to the development of the article and to the critical review of its intellectual content.

\section{Conflicts of Interest}

The authors do not declare any conflict of interest.

\section{References}

[1] Jaafar, J., Pechère-Bertschi, A. and Ditisheim, A. (2014) Pregnancy Hypertensions: Practical Considerations. La Revue Médicale Switzerland, 10, 1645-1649. 
[2] Mounier-Vehier, C., Equine, O., Valat-Rigot, A., Devos, P. and Carre, A. (1999) Hypertensive Syndromes in Pregnant Women: Pathophysiology, Definitions and Progressive Maternal-Fetal Complications. La Presse Médicale, 28, 880-885.

[3] Dayer, M., Vocat, A., Ditisheim, A. and Pechère-Bertschi, A. (2013) Renovascular Prognosis of Preeclampsia in Mothers and Children. La Revue Médicale Switzerland, 9, 1628-1632.

[4] Sengeyi, M., Lokengo, L., M’Buyamba, K. and Tandu, U. (2011) Hypertensive Disorders during Pregnancy at Cliniques Universitaires de Kinshasa. Annals of African Medicine, 4.

[5] Krzesinski, J. and Saint-Remy, A. (2012) Student Diagnostic Thumbnail, How I Measure Blood Pressure in the Consulting Room. Revue Médicale de Liège, 67, 492-498.

[6] Mounier-Vehier, C., Amar, J., Boivin, J., Denolle, T., Fauvel, J., Plu-Bureau, G., et al. (2015) HTA and Pregnancy Consensus of Experts from the French Society of Arterial Hypertension (SFHTA). http://www.sfhta.org

[7] Postel-Vinay, N. and Bobrie, G. (2008) Measuring Blood Pressure Well, Recommendations for Practice, Imothep Medicine-Science Edition.

http://www.automésure.com

[8] Reinders, A., Jones, C., Cuckson, A. and Shennan, A. (2003) The Maxi Stabil 3: Validation of an Aneroid Device According to a Modified British Hypertension Society Protocol. Blood Pressure Monitoring, 8, 83-89. https://doi.org/10.1097/00126097-200304000-00005

[9] De Greeff, A., and Shennan, A.H. (2013) Validation of the Tensoval Duo Control II Blood Pressure Monitor for Clinic Use and Self-Measurement According to the British Hypertension Society Protocol and the European Society of Hypertension International Protocol Revision 2010. Blood Press Monit, 18, 161-166.

[10] Moonen, M., Legrand, D. and Lancellotti, P. (2012) European Recommendations 2011 for the Management of Cardiovascular Diseases during Pregnancy. Revue Médicale de Liège, 67, 509-512.

[11] Randriambololona, D., Botolahy, Z., Randrianantoanina, F., Randriamahavonjy, R. and Rakotovao, H. (2009) High Blood Pressure and Pregnancy: Maternal-Fetal Prognosis. Tropical Surgical Journal, 3, 32-34.

[12] Mboudou, E., Foumane, P., Belley Priso, E., Dohbit, J., Ze Minkande, J., Nkengafac, W. and Doh, A. (2009) Hypertension during Pregnancy: Clinical and Epidemiological Aspects at the Gyneco-Obstetric and Pediatric Hospital of Yaounde, Cameroon. Clinics in Mother and Child Health, 6, 1087-1093.

[13] Doumbia, F., Traore, B. and Kone, M. (2010) Hypertension and Pregnancy in the Obstetrics and Gynecology Department of the Reference Health Center of the Commune VI. Medical Thesis, 128. http://www.keneya.net/fmpos/theses/2010/med/pdf/10M222.pdf

[14] Touré, I., Brah, F. and Prual, A. (1997) Hypertension and Pregnancy in Niger: Case Study/Witnesses about 70 Cases. Medicine in Black Africa, 44, 205-208.

[15] Thiam, M., Goumbala, M., Gning, S., Fall, P., Cellier, C. and Perret, J. (2003) Maternal and Fetal Prognosis of the Association Hypertension and Pregnancy in Sub-Saharan Africa. Journal de Gynécologie Obstétrique et Biologie de la Reproduction, 32, 35-38.

[16] Boubacar, D., Kokaina, C. and Thera, T. (2011) Hypertension on Pregnancy at Nianankoro Fomba de Segou Hospital. Medical Thesis, 116.

http://www.keneya.net/fmpos/theses/2012/med/pdf/12M80.pdf 
[17] Merviel, P., Touzart, L., Deslandes, V., Delmas, M., Coicaud, M. and Gondry, J. (2008) Risk Factors for Preeclampsia in the Event of a Single Pregnancy. Journal of Obstetric Gynecology and Reproductive Biology, 37, 477-482. https://doi.org/10.1016/j.jgyn.2008.04.001

[18] Goffinet, F. (2010) Epidemilogy on Preeclampsia. Annales Françaises d Anesthésie et de Réanimation, 29, 7-12. https://doi.org/10.1016/j.annfar.2010.02.010

[19] Pradervand, P., Feihl, F., Waeber, B. and Vial, Y. (2009) Hypertension and Pregnancy. Revue Médicale Suisse, 5, 1758-1762.

[20] Laghzaoui, M. and Puech, F. (2010) Epidemiology, Morbidity, Mortality from Preeclampsia and Eclampsia, Extract from Updates in Gynecology and Obstetrics. Journal de Gynécologie Obstétrique et Biologie de la Reproduction, 39, S1-S342.

[21] Coulibaly, K., Abhé, C., Ouattara, A., Yapi, N., Assa, N., Binlin-Dadié, R. and Brouh, Y. (2014) Complications of Pre-Eclampsia in Polyvalent Resuscitation at Cocody University Hospital (Abijan-RCI). African Journal of Anesthesiology and Emergency Medicine, Tome 19, No. 1.

[22] Sibai, B., Dekker, G. and Kupferminc, M. (2005) Preeclampsia. Seminar Lancet, 365, 785-799. https://doi.org/10.1016/S0140-6736(05)17987-2

[23] Ngwe, J., Bernard, P., Khang'Mate, F., Mwembo, A., Chenge, F., Kalenga, P., et al. (2013) Study of Risk Factors for Intrauterine Growth Retardation in Lubumbashi. Pan African Medical Journal, 14, 4.

[24] National College of French Gynecologists and Obstetricians (2013) Intrauterine Growth Retardation, Recommendations for Clinical Practice, 37th National Days, Paris.

[25] Meekins, J., Pijnenborg, R., Hanssens, M., Fadyen, I. and Asshe, A. (1994) A Study of Placental Bed Spiral Arteries and Trophoblast Invasion in Normal and Severe Pre-Eclamptic Pregnancies. British Journal of Obstetrics and Gynaecology, 101, 669-674. https://doi.org/10.1111/j.1471-0528.1994.tb13182.x

[26] Redman, C. (1991) Current Topic: Pre-Eclampsia and the Placenta. Placenta, 12, 301-308. https://doi.org/10.1016/0143-4004(91)90339-H

[27] Merviel, P., Lanta, S., Lourdel, E., Delaby, B., Lo Presti, J., Gagneur, O., Nasreddine, A., Verhoest, P., Naepels, P. and Gondry, J. (2007) Physiopathology of Severe Preeclampsia. Realities in Gynecology-Obstetrics, No. 124.

[28] Fatoumata, D., Dolo, A. and Téguété, I. (2008) Hypertension and Pregnancy in the Gynecology-Obstetrics Department of the chu Gabriel Touré from 2003 to 2006. Medical Thesis, 147. http://www.keneya.net/fmpos/theses/2008/med/pdf/08M115.pdf

[29] American College of Obstetricians and Gynecologists (ACOG) (2006) Umbilical Cord Blood Gas and Acid-Base Analysis. Obstetrics \& Gynecology, 108, 319-322. 